\title{
Da miscigenação ao pluriculturalismo: questōes em torno da ideologia pós-racial e a política da diferença no Brasil
}

\author{
From miscegenation to pluriculturalism: questions about \\ post-racial ideology and the politics of difference in Brazil
}

\author{
Alexandre Emboaba da Costa
}

\section{Resumo}

Este artigo desenvolve o conceito da ideologia pós-racial no contexto brasileiro em relação a idealização da miscigenação e a persistente defesa da democracia racial como uma futura possibilidade ameaçada pelos movimentos antirracistas e pelas políticas de reparaçōes para o povo negro brasileiro. $\mathrm{O}$ artigo apresenta dois aspectos em relação a ideologia pós-racial como estratégia de poder. Primeiro, examina a existência da defesa continuada da miscigenação e da democracia racial como possibilidade harmoniosa e igualitária num contexto onde a realidade revela a frequente desumanização e racismo contra negros/as, e um persistente fosso sócio-econômico entre afro-descendentes e euro-descendentes. Segundo, o artigo analisa as políticas públicas étnico-raciais e pluriculturais, argumentando que ao mesmo tempo que elas têm aberto possibilidades para transformação das relaçōes étnico-raciais, elas têm também representado uma institucionalização das demandas do movimento negro e um reformismo que limita a reestruturação radical da base política do estado brasileiro, do conteúdo epistemológico das políticas públicas e da participação cidadã. Especificamente, o exemplo das diretrizes para a implementação da Lei no 10.639/03 é analisado. Concluo que as políticas antirracistas e pluriculturais negras que propendem à descolonização das relações étnico-raciais necessitam o trabalho crítico e contínuo dos movimentos sociais negros, caso contrário, elas se tornarão cooptativas, incorporando a luta negra em políticas e instituiçōes delimitadas, impedindo transformaçōes sociais mais amplas.

Palavras-chave: Ideologia racial, racismo, antirracismo, miscigenação, democracia racial, pluriculturalismo, Lei 10.639, decolonialidade

\section{Abstract}

This article develops the concept of post-racial ideology in the Brazilian context in relation to idealizations of miscegenation and the persistent defense of racial democracy as future possibility threated by anti-racist movmenets and public policies of reparations for black Brazilian peoples. The article presentes two aspects of post-racial ideology as a strategy of power. First, it examines 


\begin{abstract}
the existence of a continued defense of miscegenation and racial democracy as harmonious and egalitarian possibility in a context where the reality reveals frequent dehumanization and racism against blacks and a persistent sócio-economic gap between afro-descendants and euro-descendants. Second, the article analyzes ethno-racial and pluricultural public policy, arguing that while they have opened up possibilities to transform race relations, they have also represented an institutionalization of the demands of the black movement and a reformism that limits a radical restructuring of the Brazilian state, in terms of epistemological content of policy and citizen participation. Specifically, the example of the Diretrizes Curriculares for the implementation of Law 10.639/03 is analyzed. The article concludes that black anti-racist and pluricultural policies that seek to decolonize ethno-racial relations necessitate the continued critical labor of black social movements in order to prevent that such policies become cooptative, incorporating black struggles within a delimited politics and institutions that impedes broader social transformation.
\end{abstract}

Keywords: Racial ideology, racism, anti-racism, miscegenation, racial democracy, multiculturalism, Act n. 10.639, decoloniality.

A recente conjuntura da política racial na América Latina e no Brasil envolve uma mudança de um paradigma baseado em noçōes da mistura cultural e racial, ou miscigenação, a modelos que reconhecem o caráter pluricultural das sociedades. A desigualdade étnico-racial, racismo e discriminação passaram da negação e silêncio para assuntos de debate público e políticas públicas. A questão da 'diferença' se tornou visível e central nessas mudanças. Ao mesmo tempo, apesar de não ser mais vista como realidade histórica ou atual, a questão da democracia racial continua como ideal e aspiração forte, uma possível finalidade futura e, assim sendo, um modelo social a ser preservado. Juntando-se a argumentos que renovam concepçōes idealizadas da miscigenação, a democracia racial passou a ser reconstituída como uma ideologia pós-racial no presente.

Ideologias pós-raciais são orientadas para o futuro, pregando o progresso racial e a possível transcendência de raça e racismo em detrimento da atenção aos racismos e às desigualdades atuais. Tais ideologias preferem evitar as estruturas racializadas e seus efeitos em vez de as enfrentar. Presentemente, a ideologia pós-racial não se limita à miscigenação idealizada ou à democracia racial, podendo também influenciar as formas de pluriculturalismo e as políticas de inclusão étnico-racial emergentes. Neste caso, a diferença cultural ou racial se torna recurso para administrar a diversidade e implementar a inclusão sem enfrentar as histórias e estruturas que produziram raça, etnia e cultura como fontes de divisão desigual e exclusão na sociedade moderna.

A conjuntura atual do capitalismo racializado revela a força sedutora da pós-racialidade como um dos principais desafios que as lutas políticas do movimento negro enfrentam em sua contestação da (re)produção das desigualdades raciais pela colonialidade. Por colonialidade, refiro-me à articulação da raça como um instrumento de classificação hierárquica e controle social com o desenvolvimento do capitalismo moderno, a divisão do trabalho, as formas de produção de conhecimento, as estruturas de autoridade e a produção de subjetividade (Grosfoguel, 2007; Quijano, 2000; Maldonado-Torres, 2007; Mignolo, 2000; Walsh, 2002). Racialização constitui um meio central através do qual a colonialidade molda trajetórias de 'diferença' dentro dos sistemas culturais e das estruturas institucionais que reproduzem e reforçam noçōes de superioridade / inferioridade, subalternização, e desumanidade, bem como a colonização do conhecimento (o racismo epistêmico), cosmovisōes, modos de vida, e maneiras de ser.

Quando se trata de miscigenação e multi- ou pluriculturalismo, a colonialidade influencia as maneiras que raça, subjetividade e desigualdade 
estrutural são enquadradas e tratadas. Ela dá forma à maneira que as ideologias pós-raciais mobilizam diferença racial e cultural como problemas do passado, categorias sociais problemáticas que produzem a divisão, ou problemas resolvidos através de formas de reconhecimento e inclusão que não interrogam a lógica das instituiçōes democráticas atuais ou do capitalismo moderno.

Nessa situação, para se desafiar o poder da ideologia pós-racial faz-se necessário questionar simultaneamente até que ponto a democracia racial baseada na miscigenação idealizada, ou uma igualdade racial baseada em pluriculturalismos liberais ou neoliberais realmente poderão contestar e desconstruir os efeitos perniciosos da colonialidade e do racismo, para avançar mudanças realmente transformadoras na maneira de fazer política, nas diversas instituiçōes da sociedade e da convivência em coletividade.

Este capítulo traça dois aspectos em relação ao pós-racial como ideologia e estratégia de poder no contexto Brasileiro atual. Primeiro, examina a existência da defesa continuada da miscigenação e da democracia racial como possibilidade harmoniosa e igualitária num contexto onde a realidade revela a frequente desumanização $e$ racismo, e um persistente fosso sócio-econômico entre afro-descendentes e euro-descendentes. Segundo, examino as políticas étnico-raciais e pluriculturais, argumentando que ao mesmo tempo que elas têm aberto possibilidades para transformação das relaçōes étnico-raciais, elas têm também representado uma institucionalização das demandas do movimento negro e um reformismo que limita a reestruturação radical da base política do estado brasileiro, do conteúdo epistemológico das políticas públicas e da participação cidadã. Em relação a estes aspectos do pluriculturalismo, examino o exemplo das diretrizes para a implementação da Lei nº 10.639/03 que legisla o ensinamento da história e cultura Africana e Afro-Brasileira no currículo escolar. Concluo que as políticas antirracistas e pluriculturais negras rumo à descolonização das relaçōes étnico-raciais necessitam o trabalho contínuo dos movimentos sociais negros, caso contrário, elas se tornarão cooptativas, incorporando a luta negra em políticas e instituiçōes delimitadas, impedindo transformaçōes sociais mais amplas.

\section{Ideologias pós-raciais}

O termo 'pós-racial' tem sido usado pela mídia e alguns académicos nos Estados Unidos para argumentar que as realizaçōes da luta pelos Direitos Civís que occorreu em meados do século vinte têm eliminado a necessidade de tratar da questão racial nas políticas públicas no presente, uma afirmação que ignora a persistência da desigualdade entre brancos e não-brancos (Cho 2009). Examinar a ideologia pós-racial no contexto brasileiro não significa a simples transferência de um conceito norte americano e sua aplicação em um contexto diferente. Ao contrário, situando o pós-racial na sua trajetória mais longa e ampla, ou seja, na sua emergência na América Latina, revela a ideologia pós-racial como uma estratégia de poder que se expressa de maneiras diversas em diferentes contextos das Américas. Isso demonstra a necessidade de tratar tal ideologia e seu uso político como uma questão hemisférica que hoje afeta a ação em prol da igualdade étnico-racial em contextos variados.

Designo como ideologias pós-raciais as formas de pensamento, discurso e ação que evadem, deslegitimam e tentam eliminar as questōes das diferenças raciais e seus efeitos do vocabulário e foco de estudos académicos, da luta antirracista, do debate público, e das políticas públicas. Ideologias pós-raciais, uma questão que hoje diferentemente marca diversos contextos das Américas, operam através de formas de poder racializadas que alegam a insignificância da raça e negam o racismo. Os entendimentos de pertencimento e inclusão que se desenvolvem pela pós-racialidade rearticulam em vez de transformar processos desiguais de assimilação, incorporação, cooptação e exclusão dentro do desenvolvimento nacional e global. 
Ideologias pós-raciais se baseiam principalmente na ideia do progresso e transcendência em relação á questão da raça, ou seja, na noção de que os efeitos desiguais da diferença racial foram superados, e nos casos em que as desigualdades raciais são reconhecidas como ainda existentes, poderiam ser superadas sem atenção crítica e substantiva à questão racial. A ideologia pós-racial se investe na questão do progresso racial - a minimização do racismo, discriminação, e desigualdade racial - em relação às geraçōes prévias (como nos Estados Unidos), ou ela investe na transcendência da existência da raça como fato social que organiza os pensamentos e açōes de indivíduos ou instituiçōes na sociedade (como no Brasil). Nos dois casos, a ideia do progresso e transcendência coexistem com o racismo e a discriminação contínua, obscurecendo e minimizando formas de racismo e desigualdade realmente existentes em favor da ideia de melhoria e o movimento da sociedade além da raça.

Ideologias pós-raciais também professam um 'universalismo racialmente neutro' (Cho, 2009), onde a ideia normativa da igualdade universal - 'somos todos iguais perante a lei' - projeta políticas baseadas em raça como fonte de divisão da nação. Ao mesmo tempo, uma 'equivalência moral' entre diferentes usos da 'raça' interpreta o anti-racialismo como se fosse antirracismo: negar a existência de raças significa negar o racismo como um sistema e evitar o uso da raça na política melhora a sua presença na sociedade, remove a sua visibilidade, e, em teoria, diminui seus efeitos perniciosos (Guimarães, 2001; Cho, 2009). Raça acaba parecendo uma categoria impensável da experiência social, e portanto, da legislação, enquanto a falsa percepção da igualdade de condições sustenta a ideia de que qualquer uso de 'raça' se torna racista (por exemplo, 'racismo às avessas'). Qualquer uso da raça, especialmente para políticas públicas, é caracterizada como um retrocesso ou retorno ao passado pernicioso em vez de uma necessidade a ser explicitada. Isso minimiza o racismo e acu- sa negros não só de racismo-às-avessas, mas da racialização da sociedade. A ideologia pós-racial transforma o próprio/a negro/a discriminado/a no problema racial, ofuscando as causas das desigualdades raciais.

\section{Ideologia pós-racial no Brasil: a miscigenação idealizada}

No Brasil, e em grande parte da América Latina, a ideologia pós-racial surgiu através de projetos de construção nacional que conceituaram uma nação mestiça, integradora e assimiladora de povos indígenas e afro-descendentes dentro de uma Latinidade embranquecida. No início do século XX, a miscigenação foi reimaginada como atributo positivo, hibridez antirracialista e, consequentemente, como algo inerentemente antirracista que reduz diferenças, aumenta a harmonia inter-racial, une o povo, e prevê o surgimento da democracia racial. Logo em seguida, um 'ideal antirracialista rejeitando a existência de "raças" rapidamente se fundiu com a política de negar o racismo como prática social', criando a noção de que "no Brasil existe apenas "preconceito", significando percepçōes individuais equivocadas que tendem a ser corrigidas ao longo da continuação das relaçōes sociais' (Guimarães, 2001: 158). Assim, miscigenação representou progresso, vindo a representar a transcendência de raça e do racismo.

A essencialização da figura do mestiço junto com a naturalização do discurso brasileiro de que 'somos todos mestiços' e, por isso, 'não podemos ser racistas' (por exemplo, em Kamel 2006), tem tido o efeito de delimitar articulações e valorizações de formas não-mestiças de identidade racial e subjetividade (Caldwell, 2007: 41-43; ver também Dulitzky, 2005). Ao mesmo tempo, tais discursos tem ignorando as maneiras em que a mistura não causa a desaparência das 'diferenças' Africanas, Indígenas, e Europeias em um hibridismo abrangente. Ao contrário, a mistura rearticula as diferenças através de uma dinâmica 
que simultaneamente homegeniza e diferencia, criando significados específicos e hierárquicos em relação a brancura, a negritude, e a indigeneidade (Wade, 2005).

Destaque para os elementos positivos de cordialidade e ambiguidade da mistura tornou uma 'pigmentocracia' profundamente racializada que determina status, classe, educação e origem familiar, em uma ideologia nacional antirracista que obscureceu 'a existência de um sistema extremamente eficiente de dominação racial' (Nascimento, 2007: 19; ver também Gilliam, 2003; Guimarães, 1995; Hanchard, 1994). Enquanto a diferença racial for impedida de se tornar uma base para a constituição de grupos culturalmente distintos, mesmo assim 'sustentou um discurso e práticas que constituem diferença racial como uma categoria social' onde, ao nível jurídico, econômico e simbólico da configuração social, 'as posições dos indivíduos são determinadas pelo grau de escuridão em seus corpos', especialmente as observáveis disparidades socioeconômicas que marcam as trajetórias sociais subalternas de brasileiros negros (da Silva, 2010: 18).

Essa miscigenação idealizada, que tem sido historicamente dominante, afirma que a mistura (a) elimina as bases raciais de diferença e discriminação, (b) produz o antirracialismo, ambiguidade, convívio e harmonia por enfraquecer as fronteiras raciais, (c) constitui o modelo mais viável de inclusão universal, e (d) é uma possibilidade antirracista em relação à diferença racial moralmente superior ao uso explícito da diferença para políticas contra a desigualdade racial. Esta interpretação negligencia que a mistura em si tem diversos significados e resultados, e que ela é também formada por histórias próprias de raça e relaçōes desiguais de poder.

As consequências da mistura idealizada e da democracia racial quanto formadora da ideologia pós-racial exibem o que o antropólogo João Costa Vargas (2004) denomina de a 'dialética da hiperconsciência/negação do racismo'. Essa dialética influencia a forma como os brasileiros 'pensam / reprimem, interrogam / aceitam passivamente, e justificam / ignoram as hierarquias sociais', especialmente aquelas baseadas em raça (Vargas, 2004: 444). A dialética expressa um sistema de poder que 'silencia consciência das classificações raciais e suas práticas e representaçōes decorrentes, obscurecendo o papel da raça na determinação de posiçōes nas estruturas históricas do poder e de recursos', enquanto, ao mesmo tempo, revelando a maneira que 'os brasileiros são [realmente] bem conscientes das diferenças raciais e utilizam elas (muitas vezes tacitamente) para justificar, pensar, e reforçar comportamentos e desigualdades sociais' (Vargas, 2004 : 446).

Hiperconsciência/negação expressa um sistema supostamente não-racial que tem sido historicamente de fato, e continua sendo, profundamente preocupado com o significado de raça e sua conexão com status, identidade individual e nacional, e desenvolvimento societal. Essa dialética é extremamente evidente em situações e incidentes carregadas de significados raciais (muitas vezes gritantes) onde as pessoas vejam (ou procuram ver) tudo menos raça e racismo como uma explicação.

\section{0 pós-racial como estratégia de poder: a futura promessa da democracia racial}

Uma principal via do poder pós-racial embutida na miscigenação idealizada é a ideia da possível transcendência racial, onde racismo, discriminação, e desigualdade existente são considerados um paradoxo ou enigma em um processo que culminará na insignificância da raça e na igualdade a-racial (Fry, 2007; Vianna, 2004). Esta caracterização errônea decorre de pressupostos que a miscigenação seja um processo inerentemente antirracista que levará a nação à igualdade. Ou seja, mistura torna-se um processo ativamente antirracista, algo que não necessita ser acom- 
panhada por uma consciência crítica em relação à diferença racial.

Nessa ideologia, as desigualdades raciais persistem como aberraçōes e expressōes temporárias resultantes do fato de que a mistura não teve a oportunidade de jogar-se para fora e alcançar suas 'últimas consequências libertadoras' (Vianna, 2004: 4). Racismo e desigualdade racial permanecem aspectos inconsistentes de um quadro onde mistura significa a transcendência. A consequência é a desestimulação da identificação da diferença racial e racismo como aspectos formativos de um sistema baseado na miscigenação que tenha suas próprias formas de racialização. O movimento negro há muito tempo denominou este sistema de 'racismo velado', aquele racismo sutil, implícito, e negado, com efeitos perniciosos que são tão profundos, se não forem mais profundos pela a sua invisibilidade, como os de sistemas raciais mais explícitos.

O poder do pensamento pós-racial emerge na promessa embutida na mistura idealizada para levar a sociedade além da raça por meio da igualdade quanto inclusão. A promessa constitui uma construção temporal, articulada como transição. No entanto, por elidir a persistência da diferença racial dentro da miscigenação, a crença no a-racialismo da mistura (existente e eventual) dá força a uma estratégia de poder que mobiliza diferença racial ao mesmo tempo em que declara a sua insignificância. Investimento na promessa de futuro da democracia racial impōe disciplina cruel sobre negros brasileiros na forma de espera, o que Michael Hanchard chama de 'tempo racial (racial time)', onde os benefícios da igualdade e cidadania acabarão por chegar (1999). Em vez de paradoxo ou contradição, tal lapso de tempo (ainda não foi capaz de), e a promessa (ele irá eventualmente) da mistura figura centralmente na operação desta estratégia pós-racial de poder.
O ressurgimento reacionário da miscigenação idealizada se defende como se o Brasil será desfeito (Fry 2007) e se racializará em meio de um novo ódio racial que gerará violência inter-étnica (veja por exemplo D. Magnoli em "Desigualdades"; P. Fry emStrecker, 2006; Kamel, 2006). Essas tentativas de mobilizar o ideal da democracia racial, ao mesmo tempo projetando o 'fim do Brasil', ressurgem justo no momento em que o estado começa a agir em torno dos direitos étnico-raciais, respondendo reivindicações do movimento negro após décadas de sua luta. Desta maneira, a ideologia pós-racial procura delimitar o âmbito das políticas implementadas. ${ }^{1}$

Para resumir, os efeitos principais da ideologia pós-racial incluem: (a) um antirracialismo que minimiza a importância da raça e evita encarar seus efeitos, (b) a promoção da falsa esperança / ansiedade que a transcendência torna a raça uma não-questão, um problema do passado, transformando políticas públicas étnico-raciais em proposições políticas desnecessárias, (c) a redefinição dos termos e possibilidades da política em torno da raça com profundas implicaçōes para lutas antirracistas e afins para a igualdade, e (d) a naturalização de hierarquias raciais através do status desigual, privilégio e desvantagem ligados à branquitude e à negritude.

\section{Superando a ideologia pós-racial? multiculturalismo despolitizante versus decolonialidade}

Nas últimas duas décadas na América Latina, raça, etnia, cultura e desigualdade étnico-racial surgiram como aspectos legítimos, mas debatidos, nos discursos públicos e na formulação de políticas. Diversos países têm implementado novas constituições e políticas de reconhecimento, voltadas às desigualdades, afetando afro-descen-

\footnotetext{
${ }^{1}$ Recentemente, a revista brasileira Istoé produziu uma matéria de capa 'As cotas deram certo' onde são apresentadas e desmistificadas várias críticas feitas à ideia e possíveis consequências das cotas (Segalla et. al 2013).
} 
dentes e povos indígenas. O conjunto de direitos coletivos promulgado em graus variados em diferentes países através de 'regimes de cidadania multicultural' incluem: reconhecimento formal da natureza multicultural das sociedades nacionais e da existência 'de reconhecimento étnico/ racial de subgrupos, específico do direito consuetudinário indígena como oficial direito público, direitos de propriedade coletiva (especialmente a terra), garantia da educação bilíngue, autonomia territorial ou de auto-governo, e os direitos de corrigir a discriminação racial (como a ação afirmativa na educação e emprego)' (Hooker, 2008: 279-80).

O grau varia quanto às formas de direitos recém-concedidos transformam as condiçōes do desenvolvimento capitalista, abordam as causas profundas de desigualdades étnico-raciais, transformam a governança estatal, e aumentam a participação política, autonomia e autodeterminação dos povos negros e indígenas. Um fenômeno variado com diversas expressões e práticas dependendo do contexto, o multiculturalismo (geralmente chamado 'pluriculturalismo' no Brasil) aparece em formas liberais e neoliberais, mas também de formas mais críticas e decoloniais.

Multiculturalismo liberal funciona pela tolerância, celebração e incorporação da diversidade e da diferença como atributos sociais positivos de uma maneira que muitas vezes reforça a branquitude novamente como norma dominante, reproduz clichês essencialistas, descentraliza a questão do racismo e deixa inquestionado o fracasso da democracia liberal para garantir a igualdade de direitos (Warren e Sue, 2011; veja também Bannerji, 2000). Mais recentemente, multiculturalismos neoliberais têm mobilizado a diferença cultural e racial tanto como recurso econômico como quanto meio para integrar grupos previamente excluídos e suas práticas culturais e cosmovisōes dentro do gerenciamento estatal e desenvolvimento capitalista (Hale, 2002; 2005; Walsh, 2002; 2009b). Populaçōes afro-descendentes e indígenas se tornam novos sujeitos multiculturais de uma governança hegemônica que visa controlar o conflito social e assegurar a estabilidade social para o desenvolvimento capitalista neoliberal (Hale, 2002; Walsh, 2009b; 2002).

Multiculturalismos liberais e neoliberais, semeIhante à mistura idealizada de democracia racial, constituem um tipo de ideologia pós-racial. No entanto, em vez de eliminar a 'raça', mobilizam construçōes da diferença étnico-racial e cultural despolitizadas e epistemologicamente vazias dentro de uma técnica governamental. $\mathrm{O}$ efeito é a diferença como algo a ser manejado e encorajado de uma maneira que evita lidar mais ampla e profundamente com as relaçōes históricas e contemporâneas que estruturaram o racismo e a desigualdade na sociedade. A ideia e o efeito são de reforçar ao invés de desafiar as estruturas político-econômicas e epistemológicas da raça como diferença colonial, ou seja, da colonialidade. Estas reformas também delimitam exigências radicais por autonomia ou mais participação política - pela transformação da cultura e da estrutura política da sociedade e das visōes do 'desenvolvimento'. O engajamento seletivo e circunscrito do multiculturalismo com 'diferença' a esvazia de sua possibilidade política, epistêmica e ética (Walsh 2009b), enquanto alegando que a 'inclusão' seja suficiente para combater desigualdades étnicas e raciais, ou seja, para transcender o racismo.

Apesar da despolitização e cooptação, o multiculturalismo também apresenta oportunidades para os movimentos sociais negociarem e transformarem os termos de inclusão e cidadania estimulada pelas políticas da diferença (Asher, 2009; Hooker, 2008; Walsh, 2002; 2009b; Warren e Sue, 2011). Primeiro, demandas pelo reconhecimento das sociedades como multi ou pluriculturais desafiam noçōes prévias da nação mestiça e homogênea. Tal fato dá tração às afirmaçōes de direitos coletivos e atenção ao racismo e à discriminação. Em segundo lugar, 'constitucionalismo multicultural' (Van Cott, 2000) e 'constitucionalismo pluricultural' (Baldi, 2012) de fato promulgam leis e políticas que se dirigem especificamente a comu- 
nidades marginalizadas ao mesmo tempo que redirecionam recursos não somente culturais, mas também materiais para executar a inclusão étnico-racial, a igualdade, e o bem-estar das populaçōes marginalizadas, algo que sinaliza uma mudança 'pós-neoliberal' na política étnico-raciais (French, 2009; Escobar, 2012). Em alguns casos, como observado no Equador e na Bolívia, reformas 'plurinacionais' têm aberto a possibilidade de profundas transformaçōes das leis e valores que regem a sociedade e as relaçōes com uma cidadania ativa e diversa (Baldi, 2012; Walsh, 2009a; Escobar, 2012). Terceiro, a participação indígena e negra na criação de reformas pode desencadear processos inesperados e habilitosos que as elites são incapazes de controlar (Van Cott, 2006). Quarto, as novas experiências da América Latina com o multiculturalismo desafiam o liberalismo em certas frentes e são menos evasivos em relação ao poder que as versões anteriores', problematizando oficialmente o racismo e incentivando o crescimento de espaços alternativos de onde surgem contra-discursos e visōes opositoras antirracistas (Warren e Sue, 2011: 48).

Na última década, talvez a proposta mais radical relacionada à questão da 'diferença' e transformação das relações étnico-raciais seja a interculturalidade crítica, que vai além de qualquer proposta multicultural, por surgir de um lócus diferente de enunciação, o lócus da luta indígena e afro-descendente e suas experiências de colonialidade nos Andes e vários outros lugares. Interculturalidade crítica envolve um 'projeto ético, político e epistemológico, com o objetivo de descolonização das formas de organização social, as estruturas institucionais e governamentais, bem como perspectivas de conhecimento com origem nos contextos sócio-histórico da modernidade europeia e imposta como universal durante o período colonial e neocolonial' (Boatcă e Costa, 2010: 15-6; Walsh, 2009a; 2009b; 2002).
Interculturalidade crítica é uma intervenção político-epistêmica que: (1) desafia as estruturas sociais, políticas, institucionais e epistêmicas da colonialidade, (2) torna visível e transforma as estruturas e instituiçōes que posicionam hierarquicamente grupos, práticas culturais e formas de pensamento dentro de uma lógica racial, moderna-Ocidental, e colonial; (3) surge e é construída 'a partir de baixo' das experiências vividas da colonialidade por aqueles que sofreram subalternização; e (4) envolve um processo dirigido à construção de 'outros' modos de poder, 'outros' saberes, 'outras' formas de ser e de viver, e, portanto, de uma 'outra' sociedade (Walsh, 2009b: 21-5; ver também Walsh, 2009a; Walsh, 2006; Walsh e Garcia, 2002).2

A luta pela justiça e igualdade através da interculturalidade crítica prossegue por meio do político-epistêmico e ocorre através do diálogo, da troca, do respeito mútuo, do desaprendimento e do reaprendimento, através dos quais a descolonização, ao invés da 'diferença' reificada, é a meta principal. Com a colonialidade tomando lugar central, o foco é o confronto direto com as bases formativas da raça e seus efeitos, contraposta à visão onde o foco seja uma questão de transcendência da raça e do racismo que ignora seus efeitos concretos históricos bem como no presente.

\section{Pluriculturalismos no Brasil - possibilidades e dilemas da Lei 10.639/03}

O contexto brasileiro reflete visões concorrentes influenciadas pelo multiculturalismo liberal, neoliberal e crítico, bem como a interculturalidade, indicando a existência de ambas as ideologias pós-raciais de 'inclusão' e as possibilidades de transformação decolonial. O fato de que a sociedade brasileira é multicultural é dado por certo,

2 'Outro' aqui sinaliza uma alternativa à, e subversāo do, entendimentos e implantaçōes de diferença baseados no moderno-ocidental e colonial. 'Outro' aqui 'é o que a modernidade não poderia (e ainda não consegue) pensar' (Walsh, 2006: 23). 
pois diversos grupos culturais e étnico-raciais existem dentro de uma sociedade e cultura mais ampla considerada brasileira. Brasileiros usam vários termos, incluindo pluriculturalismo, sociedade multiétnica ou pluriétnica, pluralidade cultural, e diversidade cultural para descrever a diversidade existente na sociedade e também para traçar um contraste com a ausência de diversidade dentro da instituiçōes midiáticas, políticas, educacionais, corporações privadas e outros locais de poder e prestígio, fato que não reflete a diversidade realmente existente na sociedade. Os vários entendimentos e utilizaçōes desses termos entre ativistas, funcionários públicos, políticos, e a população em geral ainda necessita ser cuidadosa e sistematicamente estudada para determinar seus conteúdos e significados, mas podemos observar os usos específicos pelo movimento negro e em documentos que regem a implementação de políticas públicas.

Ativistas do movimento negro usam o pluriculturalismo para denotar suas lutas mais críticas em torno da descolonização das instituiçōes de poder (estatais e não-governamentais) e os locais de produção de conhecimento (escolas e universidades). Tal como o multiculturalismo, o pluriculturalismo pode envolver discursos e práticas despolitizadoras, bem como ideias e práticas mais críticas. Muitas vezes, as discussões mais radicais em torno do antirracismo e pluriculturalismo entre ativistas do movimento negro refletem uma orientação decoIonial que espelha o conteúdo e a prática da interculturalidade crítica que surgiu dos movimentos indígenas da região andina. Tal como dito acima, a questão decolonial envolve uma intervenção que vai além da busca pela inclusão dentro do sistema vigente e da pluriculturalização superficial das instituições, buscando uma transformação profunda na concepção de viver junto na sociedade e de organizar as esferas políticas e sociais.
A área de educação apresenta um exemplo significativo do avanço de esforços pluriculturais críticos promovidos por ativistas do movimento negro, educadores e organizaçōes não governamentais. Enfoques importantes incluem: (1) a abordagem de discursos e práticas racistas nas escolas, corrigindo representaçōes problemáticas da África e brasileiros negros nos livros didáticos, inserindo um tratamento mais substantivo do papel histórico dos negros brasileiros no currículo, (2) a incorporação de práticas e formas de cultura e conhecimento afro-descendente nos currículos escolares que afirmam diversas origens, produçōes e formas de conhecimento. Cada vez mais surgem pesquisas produzidas 'de baixo' por afiliados e aliados de casas de candomblé, academias de capoeira e organizaçōes carnavalescas, pedagogias alternativas e conhecimentos decorrentes de comunidades negras que podem diversificar pedagogias e epistemologias na sala de aula ${ }^{3}$, (3) o estabelecimento de escolas alternativas comunitárias que praticam educação intercultural e afrocêntrica ${ }^{4}$ e (4) a elaboração e implementação de programas de formação de educadores, produção de materiais e desenvolvimento de oficinas para implementar a Lei Federal no 10.639/03, que exige o ensino da cultura e história africana $e$ afro-descendente no currículo.

\section{As Diretrizes Curriculares para implementação da Lei 10.639/035}

A Lei Federal 10.639/03, assinada pelo presidente Lula durante seus primeiros dias no cargo, exemplificou um marco significante para a luta negra dentro de um sistema de ensino que os invisibilizava e excluía do conteúdo escolar. Um ano depois, um conjunto de diretrizes foram instituídas para delinear o conteúdo e a prática da implementação da Lei: as Diretrizes Curriculares

\footnotetext{
${ }^{3}$ Ver, por exemplo: Botelho (2006); Cavalleiro (2001); Gonçalves e Silva (2005); Machado (2003); Machado (2006); Santos e Luz (2007).

${ }^{4}$ Ver, por exemplo, Almeida (2003); King-Calnek (2006); Machado (2002); Santos e Luz (2007).

${ }^{5}$ A Lei no 11.645/2008 deu nova redaçāo a esta lei, incluindo também o estudo das lutas, da história e da cultura indígena, mas o foco, neste artigo, diz respeito às questōes afrodescendentes.
} 
Nacionais para à Educação das relaçōes ÉtnicoRaciais e parágrafo o Ensino de História e Cultura Afro-Brasileira e Africana, o Parecer CNE / CP 3/20046 (Brasil, 2005).

As Diretrizes são explicitamente antirracistas, desafiam o branqueamento e racismo anti-negro na sociedade e no sistema de ensino, e defendem uma concepção pluricultural da sociedade. As Diretrizes envolvem um duplo movimento de desconstrução e reconstrução, de desaprender e reaprender, visando o racismo nos materiais educativos, na sala de aula, no conteúdo curricular e nas relaçōes entre alunos, ao mesmo tempo revalorizando a história, a cultura e formas de conhecimento afro-descendentes como temas relevantes e valiosos. As Diretrizes também declaram um papel ativo para o movimento negro desempenhar na implementação de reformas, afirmando a sua perícia e epistemologias subalternas como recursos necessários para o processo. As Diretrizes, assim, contestam a institucionalização de várias camadas de inferioridade negra, desumanização e invisibilidade, propondo conteúdo potencialmente transformador da produção de conhecimento e de seus efeitos sobre alunos(as) (Da Costa, n.d.; Oliveira e Candau, 2010).

Epistemologicamente, as Diretrizes confrontam a ideologia pós-racial brasileira que caracteriza a nação como produto cultural e racialmente harmonioso da miscigenação. Tornando visível as desigualdades raciais e as formas de desvantagem e marginalização 'criad[as] e mantid[as] por uma estrutura excludente e discriminatória social' (Brasil, 2005: 12), o reconhecimento da diferença pautada pelas Diretrizes vai além da conversa superficial de valorização da diversidade para repensar os fundamentos epistemológicos da desigualdade e dos conteúdos e das práticas pedagógica. Neste sentido, buscam compromisso com cosmovisões e vivências de comunidades marginalizadas em suas especificidades históri- cas e locais como expressōes de conhecimento, sociabilidade, e entendimentos diversos do que significa ser brasileiro. $\mathrm{O}$ reconhecimento quebra a invisibilidade histórica, visa tornar o racismo institucionalizado visível em suas formas tácitas e explícitas e mobiliza reformas pedagógicas rumo a uma educação inclusiva e relevante para estudantes afro-descendentes, transformando as hierarquias raciais naturalizadas pela maioria dos estudantes e educadores de todas as cores. Ao mesmo tempo, a sabedoria negra pode ampliar e fortalecer possibilidades teóricas e pedagógicas para a educação brasileira como um todo.

Em termos da dimensão material, dois elementos se revelam na questão do reconhecimento pautada nas Diretrizes. Primeiro, existe a demanda pelos recursos estatais para refazer os currículos do ensino primário e secundário, equipar as escolas com materiais suficientes, infraestrutura e pessoal para garantir uma educação de qualidade que valoriza a diversidade e para preparar os educadores e administradores com conhecimento necessários para implementar a Lei 10.639/03. Em segundo lugar, tratar os silêncios curriculares, estereótipos negativos e racismo juntamente com a valorização da história Africana e Afro-brasileira cria um espaço mais acolhedor para estudantes negros(as), algo que ajuda a construir a autoestima e a identidade positiva que quebra a internalização da inferioridade, que contribui para o absentismo e menores taxas de sucesso acadêmico, portanto, melhorando a possibilidade do futuro sucesso sócio-econômico e bem-estar.

As Diretrizes também implicam ambos, afro-descendentes e brancos, no processo de descolonização, apontando como as ideologias da democracia racial e branqueamento criam associaçōes hierárquicas entre europeísmo (branquitude) e africanidade (negritude) que afetam todos os brasileiros. Este entendimento de raça é relacional, dissipando a noção de que a questão étnico-

\footnotetext{
${ }^{6}$ Acesível na página do Ministério da Educaçāo: http://portal.mec.gov.br/cne/arquivos/pdf/003.pdf (accessado em 10 de abril, 2013).
} 
-racial é apenas uma 'questão dos negros' ou de interesse somente para o movimento negro. As Diretrizes argumentam que:

Pedagogias de combate ao racismo e discriminações elaboradas com o objetivo de educação das relaçōes étnico/raciais positivas têm como objetivo fortalecer entre os negros e despertar entre os brancos a consciência negra. Entre os negros, poderão oferecer conhecimentos e segurança para orgulharem-se da sua origem africana; para os brancos, poderão permitir que identifiquem as influências, a contribuição, a participação e a importância da história e da cultura dos negros no seu jeito de ser, viver, de se relacionar com as outras pessoas, notadamente as negras (Brasil, 2005: 16).

Consciência negra aqui envolve uma interculturalidade que evita noções de que a consciência negra simplesmente envolve negros assumindo uma 'identidade negra'. Não se limitando a afro-descendentes, a consciência sugerida acima tem base em um senso compartilhado de história, cultura e pertencimento que apoia uma possibilidade intercultural transversal que não abre mão da atual importância de enfrentar diretamente a raça, colonialidade e ideologias pós-raciais.

A atenção à diferença, neste caso, é inclusiva e não exclusiva, algo que negros e brancos podem compartilhar como um meio para o respeito, compreensão mútua e transformação social através de uma luta comum pela igualdade. Localizar a consciência negra, desta forma, diversifica seu conteúdo, tornando-a também uma forma de auto-reflexividade que leva brancos a questionarem sua posição de vantagem/poder e negros a afirmarem como positivas sua herança e cor da pele, ambos refletindo sobre as histórias e experiências que diferenciam bem como as que ligam as pessoas. Esta conceituação relacional da raça fortalece a ênfase das Diretrizes que visa o envolvimento de todos os educadores, independentemente da sua origem étnica ou racial, em estratégias para combater racismo e desigualdade. A 'consciência negra' proposta explicitamente envolve questōes de 'identidade', mas, ao invés de sinalizar uma política de identidade, expressa uma visão mais ampla, mais profunda e multifacetada para atuar na direção da descolonização da educação.

A visão para a transformação mais profunda apresenta-se nas mudanças estruturais no sistema de ensino sugerido pelas Diretrizes em sua seção intitulada 'Ações Educativas de Combate Ao Racismo e a Discriminaçōes' (páginas 19-26). Primeiro, ela sugere temas específicos para implementar a 10.639/03: conteúdos curriculares e projetos, formas de monitorar, avaliar e compartilhar experiências de implementação, tipos de apoio que sistemas escolares devem proporcionar aos educadores, conteúdo para cursos de formação de professores e pesquisas necessárias para criar materiais pedagógicos adequados para a implementação. Segundo, ela afirma a necessidade de dar centralidade ao tema étnico-racial, desde os projetos políticos pedagógicos escolares e municipais até os órgãos do poder público à pesquisa, documentação e desenvolvimento pedagógico em relação aos afro-descendentes, incluindo o exame dos programas universitários de pedagogia para incluírem o tema das relações étnico-raciais e história negra e africana.

As Diretrizes preservam a autonomia de tomada de decisão das escolas, sistemas municipais de educação e seus funcionários/agentes de executar a implementação, facilitando a colaboração com os pais de alunos e organizações comunitárias para fazer alteraçōes relevantes às necessidades locais e contextos. Ao mesmo tempo, organizaçōes do movimento negro e Núcleos de Estudos Afro-Brasileiros (NEABs) devem prestar apoio a estas pessoas e instituiçōes, incluindo orquestrar programas de formação de professores, elaborar materiais didáticos e desenvolver programação pedagógica. A articulação entre centros de pesquisa, organizaçōes negras e escolas prevê interaçōes construtivas entre as instituiçōes do estado, comunidades e movimentos sociais na esfera local. No entanto, o envolvimento do mo- 
vimento negro não deve substituir a responsabilidade dos diretores, coordenadores e professores para implementar, monitorar e avaliar os esforços. Entidades estatais devem desempenhar um papel ativo na criação das condições financeiras e políticas necessárias para implementar a Lei.

Em suma, as Diretrizes fornecem princípios abrangentes para reconfigurar a educação ao longo das linhas pluriculturais e interculturais que reflitam perspectivas desenvolvidas através de décadas de trabalho de ativistas, acadêmicos críticos e educadores. Orquestrar as mudanças estruturais necessárias, que envolvem repensar a epistemologia e produção de conhecimento, bem como reorientar prioridades e recursos, sugere uma tarefa monumental que exige ainda mais trabalho difícil entre o estado e a sociedade em relação à causa da educação e da igualdade.

\section{Dificuldades de implementação}

Apesar de existirem legislação e diretrizes claras, levou-se cerca de três anos para aparecerem esforços visíveis e sistemáticos para a execução da Lei 10.639/03. Uma década depois, a mudança institucional no nível municipal na maioria do país prossegue lentamente, sobretudo no que diz respeito à modificação profunda do currículo e formação continuada de educadores. Devido ao lento progresso na implementação da Lei 10.639/03 em seus primeiros seis anos, a SEPPIR, criou, em 2009, a Subsecretaria de Políticas de Açōes Afirmativas (SubAA) e, em parceria com o Ministério da Educação (MEC), criou o Plano Nacional de Implementação das Diretrizes Curriculares Nacionais para Educação das Relaçōes Etnicorraciais e para o Ensino de História e Cultura Afrobrasileira e Africana ${ }^{7}$ (Brasil, 2009). Este plano define metas e estratégias de implementação nacional, incluindo 'as diferentes responsabilidades dos poderes execu- tivos, dos legislativos e dos conselhos de educação municipais, estaduais e federal no processo', e trabalha 'na perspectiva de três açōes principais: formação dos professores, produção de material didático e sensibilização dos gestores da educação' (SEPPIR, 2009).

No presente, a consciência prática da Lei existe somente nos municípios que promoveram trabalho sólido em torno da temática étnico-racial, geralmente aqueles com fortes organizaçōes negras. Em muitos casos, a autonomia dada às escolas para determinar a aplicação da Lei continua sendo um impedimento dado à resistência de muitos coordenadores pedagógicos, diretores de escolas e professores. Além disso, enquanto muitos educadores negros e brancos se tornam mais perspicazes em relação à questão racial $e$ entusiasmados pela questão da diferença e diversidade, a circulação continua sendo de discursos e açōes expressando tendências liberais que evitam críticas mais profundas, exemplificados como 'tolerância', 'respeito pela diferença' e 'aceitação do outro'. A continuada negação, por muitos, da significância da raça, somada aos orçamentos municipais carentes e à sobrecarga dos professores, fazem com que a atenção para a desigualdade racial pareça pouco importante ou de certa forma até uma indulgência.

Ademais, o repensar epistemológico proposto pelas Diretrizes confere aos povos subalternizados um estatuto epistemológico que pode gerar confusão entre os funcionários, educadores e estudantes, bem como provocar reaçōes conservadoras, 'pois se trata de um profundo questionamento a uma interpretaçāo histórica hegemônica que perpetrou uma "rejeição ontológica do outro"' (Moore, 2007; citado em Oliveira e Candau, 2010: 34). Em suma, enquanto a Lei legitima mudanças, e as Diretrizes delineiam perspectivas críticas, os desafios decoloniais robustos e transformadores ao pensamento pós-racial continuam difíceis:

\footnotetext{
${ }^{7}$ Disponível em: http://www.seppir.gov.br/.arquivos/leiafrica.pdf
} 
uma dificuldade que o movimento negro e outras organizaçōes que trabalham com a questão étnico-racial continuam tentando corrigir.

\section{A luta continua - a decolonialidade como política sem garantias}

Nossa concepção de política, nos ensina Exú, é a própria concepção do movimento, do caracol do tempo em constante ascensão e mutação, no constante conflito dos contrários que gera o novo, novos momentos, novas lutas. É o confronto dos diferentes rumos à transformação.

- Centro Cultural Orúnmila, Ribeirão Preto, São Paulo

Embora apresentando novas possibilidades para combater um sistema de racismo velado baseado na miscigenação e na democracia racial, análises recentes de experiências com reformas pluriculturais em relação a afro-descendentes na América Latina nos últimos vinte anos apontam para dilemas causados pela institucionalização do pluriculturalismo e a incorporação das demandas de movimentos sociais negros dentro da estrutura do estado (Cárdenas, 2012; Da Costa, n.d.; de la Torre e Sánchez, 2012; Escobar, 2012; Walsh, 2012). No Brasil de hoje, as possibilidades transformadoras que surgem dos esforços do movimento negro enfrentam barreiras diversas, incluindo discursos despolitizantes acerca de 'diversidade' e 'inclusão', uma continuada insistência na miscigenação idealizada por intelectuais e políticos da direita, uma estrutura de participação e tomada de decisão política que permanece elitista, paternalista e populista, bem como a diversidade de organizaçōes negras com uma gama de projetos políticos, alguns dos quais legitimam e reforçam as condições dominantes de inclusão ditadas pelo Estado.

Esses diversos fatores contextuais e atores sociais que configuram o funcionamento do pluriculturalismo manifestam a política antirracista e o 'pluriculturalismo negro' como uma articulação complexa sem garantias, um processo aberto $e$ contingente que pode ser aproveitado para fins de transformaçōes radicais ou conservadoras (Cárdenas, 2012; veja também Jhally e Hall, 2002). Por ser uma política sem garantias, o pluriculturalismo negro orientado para a decolonialidade necessita da constante atuação dos movimentos negros, de maneira a lutar simultaneamente de baixo e de cima, por fora e por dentro dos discursos e instituiçōes do Estado, expandindo e rearticulando as noçōes dominantes de participação e cidadania ao mesmo tempo que se esforçam para ultrapassar os limites apresentados pelos discursos e pelas instituiçōes existentes.

Esta situação complexa, que envolve movimentação, contestação, e luta contínua sinaliza o que poderíamos chamar de 'o decolonial na prática', isto é, um campo de contradiçōes, dilemas e desafios enfrentados no processo de encenar políticas político-epistêmicas na busca de transformação social através da descolonização de diferença, formas de pertencimento e coletividade, e a política do Estado. Em outras palavras, o decolonial, na prática, não é nada menos do que a ação inspirada e guiada pela sabedoria ancestral que Exú nos transmite: o movimento que abre novos caminhos.

\section{Bibliografia}

Afropress. 2007. Desigualdades. Available at: http://afropress.com.br/post.asp?id=13901 (accessed Date Accessed).

Almeida AFJd. 2003. Unveiling the Mirror: Afro-Brazilian Identity and the Emergence of a Community School Movement. Comparative Education Review 47(1): 41-63.

Asher K. 2009. Black and Green: Afro-Colombians, Development, and Nature in the Pacific Lowlands, Durham, NC: Duke University Press.

Baldi CA. 2012. New Latin American Constitutionalism: Challenging Eurocentrism \& Decolonizing History. Critical Legal Thinking: Law \& the Political. (accessed March 13, 2012).

Bannerji H. 2000. The Dark Side of the Nation: Essays on Multiculturalism, Nationalism and Gender, Toronto: Canadian Scholar's Press.

Boatcă M e Costa S. 2010. Postcolonial Sociology: a Research Agenda. In: Rodriguez EG, Boatcă M e Costa S 
(eds) Decolonizing European Sociology: Transdisciplinary Approaches. Burlington: Ashgate Publishing.

Botelho D. 2006. Orixás/Inquices/Noduns e perspectivas educacionais. İrohìn 11(8): 16-17.

Brasil. 2005. Diretrizes Curriculares Nacionais para a Educação das Relaçōes Étnico-Raciais e para o Ensino de História e Cultura Afro-Brasileira e Africana. In: Educação/ SECAD Md (ed). Brasília, DF.

Brasil. 2009. Plano Nacional de Implementação das Diretrizes Curriculares Nacionais para Educação das Relaçōes Etnicorraciais e para o Ensino de História e Cultura Afrobrasileira e Africana. In: Ministério da Educação/SECAD SEdPdPdIR (ed). Brasília.

Caldwell KL 2007. Negras in Brazil: Re-Envisioning Black Women, Citizenship, and the Politics of Identity, New Brunswick, NJ: Rutgers University Press.

Cárdenas R. 2012. Multicultural Politics for Afro-Colombians: An Articulation "Without Guarantees". In: Rahier JM (ed) Black Social Movements in Latin America: From Monocultural Mestizaje to Multiculturalism. New York: Palgrave Macmillan, 113-133.

Cavalleiro E. 2001. Racismo e anti-racismo na educação: repensando nossa escola, São Paulo Selo Negro Ediçōes.

Cho S. (2009) Post-Racialism. lowa Law Review 94: 1589-1649.

Da Costa AE. (sem data) From Racial Democracy to Multiculturalism: Black Brazilian Struggles to Decolonize Difference: manuscrito não publicado em análise com editora.

da Silva DF. 2010. The End of Brazil: An Analysis of the Debate on Racial Equity on the Edges of Global Market Capitalism. National Black Law Journal 21(3): 1-18.

de la Torre C e Sánchez JA. 2012. The Afro-Ecuadorian Social Movement: Between Empowerment and Co-optation. Black Social Movements in Latin America: From Monocultural Mestizaje to Multiculturalism. New York: Palgrave Macmillan.

Dulitzky AE. 2005. A Region in Denial: Racial Discrimination and Racism in Latin America. In: Dzidzienyo A e Oboler S (eds) Neither Enemies nor Friends Latinos, Blacks, Afro-Latinos. New York: Palgrave Macmillan, 39-59.

Escobar A. 2012. Latin America at a Crossroads: Alternative modernizations, post-liberalism, or post-development? Cultural Studies 24(1): 1-65.

French JH. 2009. Legalizing Identities: Becoming Black or Indian in Brazil's Northeast: University of North Carolina Press.

Fry P. 2007. Undoing Brazil: Hybridity Versus Multiculturalism. In: Naro NP, Sansi-Roca R e Treece DH (eds) Cultures of the Lusophone Black Atlantic. New York: Palgrave Macmillan, 233-249.

Gilliam A. 2003. Globalization, Identity, and Assaults on Equality in the United States. Souls: a Critical Journal of Black Politics, Culture, and Society 5(2): 81-106.

Gonçalves e Silva PB. 2005. Aprendizagem e Ensino das Africanidades Brasileiras. In: Munanga K (ed) Superando o Racismo na Escola. 2nd ed. Brasília: MEC, SECAD, 155-172.

Grosfoguel R. 2007. The Epistemic Decolonial Turn: Beyond Political-Economy Pardigms. Cultural Studies 21(2-3): 211-223.

Guimarães ASA. 1995. Racism and Anti-Racism in Brazil: A Postmodern Perspective. In: Bowser BP (ed) Racism and Anti-Racism in World Perspective. Thousand Oaks, CA: Sage Publications, 208-226.

Guimarães ASA. 2001. The Misadventures of Nonracialism in Brazil. In: Hamilton CV, Huntley L, Alexander N, et al. (eds) Beyond Racism: Race and Inequality in Brazil, South Africa, and the United States. Boulder, Co: Lynne Rienner Publishers.

Hale CR. 2002. Does Multiculturalism Menace? Governance, Cultural Rights and the Politics of Identity in Guatemala. Journal of Latin American Studies 34(03).

Hale CR. 2005. Neoliberal Multiculturalism. Political and Legal Anthropology Review 28(1): 10-19.

Hanchard M. 1999. Afro-Modernity: Temporality, Politics, and the African Diaspora. Public Culture 11(1): 245-268.

Hanchard MG. 1994. Orpheus and Power: The Movimento Negro of Rio De Janeiro and São Paulo, Brazil, 1945-1988, Princeton, NJ: Princeton University Press.

Hooker J. 2008. Afro-descendant Struggles for Collective Rights in Latin America: Between Race and Culture. Souls 10(3): 279-291.

Jhally S e Hall S. 2002. Race: the Floating Signifier. Northampton, MA: Media Education Foundation.

Kamel A. 2006. Não Somos Racistas: Uma Reação aos que Querem nos Transformar numa Nacão Bicolor, Rio de Janeiro: Editora Nova Fronteira.

King-Calnek J. 2006. Education for Citizenship: Interethnic Pedagogy and Formal Education at Escola Criativa Olodum. The Urban Review 38(2): 145-164.

Machado V. 2002. llé Axé, Vivéncias e Invenção Pedagógica: as Crianças do Opó Afonjá, Salvador: EDUFBA.

Machado V. 2003. Por uma pedagogia nagó. In: Fonseca DPRd (ed) Resisténcia e Inclusão: história, cultura, educação e cidadania afro-descendentes no Brasil e nos Estados Unidos. Rio de Janeiro: Pontificia Universidade Catolica, 119-137. 
Machado V. 2006. Àqueles que têm na Pele a Cor da Noite: Ensinâncias e Aprendências com o Pensamento Africano Recriado na Diáspora. Faculdade de Educação. Programa de Pós-graduação em Educação. . Salvador, BA: Universidade Federal da Bahia.

Maldonado-Torres N. 2007. On the Coloniality of Being: Contributions to the Development of a Concept. Cultural Studies 21(2): 240-270.

Mignolo W. 2000. Local Histories/Global Designs: Coloniality, Subaltern Knowledges, and Border Thinking, Princeton, N.J: Princeton University Press.

Moore C. 2007. Racismo e Sociedade: Novas bases epistemológicas para entender o Racismo, Belo Horizonte: Mazza Ediçōes.

Nascimento EL 2007. The Sorcery of Color: Identity, Race, and Gender in Brazil, Philadelphia: Temple University Press.

Oliveira LFd e Candau VMF. 2010. Pedagogia Decolonial e Educação Antirracista e Intercultural no Brasil. Educação em Revista 26(1): 15-40.

Orùnmilá CC. 2006. Editorial. Sorò Dúdú: Fala Negro (November): 2.

Quijano A. 2000. Coloniality of Power, Eurocentrism, and Latin America. Nepantla: Views from South 1(3): 533-580.

Santos DMd e Luz MA. 2007. Oba Biyi, o rei nasce aqui: a educação pluricultural africano-brasileiro, Salvador: Fala Nagô.

Segalla A, Brugger M e Cardoso R. 2013. Por que as cotas raciais deram certo no Brasil. Istoé. 10 April ed.

SEPPIR. (2009) Plano Nacional de Implantação da Lei no 10.639. Available at: http://www.seppir.gov.br/acoes/plano_10639. (accessed Date Accessed).

Strecker M. 2006. A cor da igualdade. Folha de São Paulo. Van Cott DL 2000. The Friendly Liquidation of the Past the Politics of Diversity in Latin America: Univ of Pittsburgh Press.

Van Cott DL 2006. Multiculturalism versus neoliberalism in Latin America. In: Kymlicka W e Banting KG (eds) Multiculturalism and the Welfare State. Oxford University Press, 272-296.
Vargas JHC. 2004. Hyperconsciousness of Race and Its Negation: The Dialectic of White Supremacy in Brazil. Identities 11(4): 443-470.

Vianna H. 2004. Mestiçagem fora do lugar. Folha de São Paulo. June 24, 2004 ed. São Paulo, 4-6.

Wade P. 2005. Rethinking Mestizaje: Ideology and Lived Experience. Journal of Latin American Studies 37(2): 239-257.

Walsh C. 2006. Interculturalidade y colonialidad del poder. Un pensamiento y posicionamiento otro desde la diferencia colonial. In: Walsh C, García Linera Á e Mignolo W (eds) Interculturalidad, descolonización del Estado y del conocimiento Buenos Aires: Editorial Signo, 21-70.

Walsh C. 2009. Interculturalidad, estado, sociedad : luchas (de)coloniales de nuestra época, Quito: Universidad Andina Simón Bolívar; Ediciones Abya-Yala.

Walsh C. 2009. Interculturalidade Crítica e Pedagogia Decolonial: in-surgir, re-existir e re-viver. In: Candau VM (ed) Educação Intercultural na América Latina: entre concepçōes, tensōes e propostas. Rio de Janeiro: 7Letras.

Walsh C. 2012. Afro In/Exclusion, Resistance, and the "Progressive" State: (De)Colonial Struggles, Questions, and Refletions. In: Rahier JM (ed) Black Social Movements in Latin America: From Monocultural Mestizaje to Multiculturalism. New York: Palgrave Macmillan, 15-34.

Walsh C e Garcia J. 2002. El pensar del emergente movimiento afroecuatoriano: Reflexiones (des)de un proceso. In: Mato D (ed) Estudios y otras prácticas intelectuales latinoamericanas en cultura y poder. Caracas, Venezuala: CLACSO, Consejo Latinoamericano de Ciencias Sociales.

Walsh CE. 2002. The (Re)articulation of Political Subjectivities and Colonial Difference in Ecuador: Reflections on Capitalism and the Geopolitics of Knowledge. Nepantla 3(1): 61-97.

Warren JW e Sue CA. 2011. Comparative racisms: What anti-racists can learn from Latin America. Ethnicities 11(1): 32-58.

Alexandre Emboaba da Costa

Assistant Professor. Theoretical, Cultural, and International Studies in Education. Department of Educational

Policy Studies. University of Alberta - Canada. 